\title{
Air Route Suspension: \\ The Role of Stakeholders' Engagement and Aviation and Non-aviation Factors
}

\author{
Camila Vianna \\ Flight Centre Group, Australia \\ Email: camila_vianna@flightcentre.com
}

\author{
Gui Lohmann \\ Griffith Aviation \\ Griffith University, Australia \\ Email: g.lohmann@griffith.edu.au
}

\begin{abstract}
Air route suspension has rarely been examined in the academic literature. To address this void, this study provides insight into how both aviation and non-aviation factors affect the decision to suspend domestic air routes in Australia. It also analyses the business relationships and negotiation processes followed by airports, airlines, and destination management organizations (DMOs) to avoid air route suspensions. Data were collected through semi-structured interviews with key aviation and tourism stakeholders directly affected by suspended routes. The outcomes of this paper demonstrate that although most of the major reasons for air route suspension in Australia are mentioned in the existing literature and are linked to demand, other factors have not
\end{abstract}


been deeply investigated, including how stakeholders can prevent the suspension of air routes. This paper also explores and identifies strengths and weaknesses in the relationship among airlines, DMOs and airports.

Keywords: airlines; Australia; route suspension; tourism; domestic routes 


\section{Introduction}

Since the 1960s, aviation and tourism have developed a strong mutual dependency; both industries rely on each other considerably to sustain their development (Duval, 2013; Lohmann and Duval, 2014). This is even more evident in the case of countries with strong domestic markets (Koo and Lohmann, 2013), insular destinations (Liasidou, 2013), remote regions (Bråthen and Halpern, 2012) and international, long-haul-dependent economies (Becken and Lennox, 2012). A large body of the academic literature on the aviation-tourism connection focuses on the enabling factors that facilitate air service development, particularly in regard to multi-/bi-lateral air service agreements (ASA) — in broader terms of what Duval (2013) has labelled aeropolitics_-liberalization (Dobruszkes and Mondou, 2013; O’Connell and WarnockSmith, 2012) and the facilitation of geographic connectivity and availability (Duval and Schiff, 2011). However, the understanding of 'why' air routes fail and are suspended is largely ignored by the academic literature despite the obvious importance of learning from unsuccessful experiences. Even industry reports provide little information that would enable a comparison of air routes that are suspended versus services that are suspended.

Despite the importance of understanding the procedures for the suspension of air transport, the academic literature provides no framework for analysing the decision-making process and the role of different factors and stakeholders in this process. Other studies examining this topic have analysed the procedures of developing air routes (Swan, 2002) or some aspect of maintaining operating air routes (Calderón, 1997). Regional airport characteristics have also been 
studied (Baker and Donehue 2012) and flight frequency has been thoroughly investigated (Hsu and Wen 2007). However, there is scant literature relating specifically to air route suspension and therefore this study makes a central contribution to filling that gap. Importantly, in this paper, the term 'route suspension' refers to routes that airlines have no plans to reinstate. We purposely declined to use the term 'cancellation,' which among some aviation professionals connotes a more temporary status. We also do not include cases in which an entire airline is grounded and its network is affected on multiple fronts; we focus on only individual cases of route suspension.

This paper investigates the decision-making process related to domestic air route suspensions in Australia using examples and cases between 2008 and 2013 as we seek to determine what aviation and non-aviation factors influence decisions related to predominantly leisure-travel routes. In this regard, Australia is a suitable case study on air route suspension both because it has a large, mature domestic-travel market and because tourism is one of its main economic powerhouses. We identify the roles of stakeholders, including airports and destination management organizations (DMOs), in supporting airlines’ attempts to avoid such suspensions. This focus is particularly relevant because second- and third-tier destinations struggle to compete with the primarily urban, wealthier destinations that are likely to invest resources to crosssubsidise marketing initiatives that support airlines in promoting their destinations. This paper is structured as follows. The next section investigates previous descriptions of the reasons for air route suspension and the relationships among relevant stakeholders. The following section discusses the methodological aspects of the study, after which we present the results and draw conclusions. 


\section{Air Route Suspension Factors and Stakeholders}

Considering the overall absence of the topic of air route suspension in the academic literature, an exploratory literature review that identifies the relevant factors associated with this theme is required. In many aspects, this literature draws from the broader understanding of demand and factors that influence travel in general, and other specific aviation-related matters are also worth analysing. This review is also conducted to map out the various stakeholders and their functions associated with this topic. Discussing the relationship between factors in air route suspension and the role and engagement of various stakeholders is paramount prior to contextualizing them in Australia’s domestic market. This section concludes by proposing a framework to analyse the themes of this research.

\section{Air Route Suspension Factors}

Undoubtedly, the interconnection between air route suspension and traveller demand is important. Air route suspension directly affects the overall travel experience of airline passengers, particularly that of 'time-sensitive' customers who would not have travelled by other means of transport. Simultaneously, lack of demand is a major decision factor when considering the decision to suspend routes. Several factors are associated with the decision to suspend a route from the perspective of demand (Hsu and Wen 2003), and they should be examined further, which Wang and Song (2010) have done in a comprehensive review of 150 journal articles. Based on the literature review conducted for this study, a conceptual framework of the factors that influence traveller demand was developed (see Figure 1).

Pearce (2012) explains that conceptual frameworks 'set out the key concepts and factors to be investigated' (p. 13) and are particularly useful with respect to 'emerging, fragmented or broad themes' (p.28), which is the case for air transport route suspension. For this research, 
developing a conceptual framework is particularly useful to map out the relationships among the factors of air route suspension. The conceptual framework proposed in Figure 1 divides air travel demand factors using Calderón’s (1997) two primary groups of drivers that influence air travel demand: aviation and non-aviation related factors, the latter of which are called 'geo-economic' factors.

[Figure 1 about here]

Aviation factors. Numerous factors are either directly or indirectly associated with an airline's ability to maintain or suspend a route. The main factor is overall airline profitability and particularly route profitability, which are affected by non-aviation/geo-economic factors that influence the general population's income level. Directly associated with airline/route profitability are the financial resources available to the airline-i.e., whether it has enough cash to anticipate or delay route suspension decisions—and its overall business strategies; airlines can change their business models to make some routes less appealing. Thus, correctly assessing yield and revenue analysis is paramount, particularly to reach break-even points.

The service provided by the airline, defined as a combination of quality and price (Calderón 1997), can also influence a route’s long-term sustainability. Quality includes services such as frequency and time of departures; load factor; aircraft size, type or technology; and inflight entertainment/amenities (Tretheway and Oum, 1992; Wang and Song, 2010). Yang, Karaesmen and Keskinocak (2010) also note that airlines have limited options and resources to cope with disruptions in terms of airplane availability and scheduling arrangements and to manage their assets to be available for more profitable routes. Thus, one can consider that the 
optimization of aircraft utilization and crew availability play a role when airlines must prioritize which routes to maintain or suspend. Pricing is a complex decision-making process for airlines that usually not only reflect a chosen business model (Lohmann \& Koo, 2013) but also are affected by a combination of aviation and non-aviation factors, including the level of service provided, seasonality, slot availability, costs and taxes, aviation and non-aviation competition, yield-management strategies and market characteristics (Peoples, 2012), which are presented in this literature review.

Competitive power and market penetration from low-cost carriers (LCCs) and competition with other modes of transport have both had a significant effect on air route suspension. LCCs take advantage of their focus on cost to choose secondary airports and target destinations that offer concession incentives or aviation-fee reductions to favour the most costefficient routes (Smyth et al. 2012). By targeting numerous leisure destination markets, which are interested in supporting transport accessibility for the benefit of the tourism industry and competing against each other, LCCs use their mobile assets to threaten or actually to relocate routes in the search for the most favourable opportunities (Olischer and Dörrenbächer, 2013). Outside of air transport, the introduction of high-speed rail services in many countries and regions of the world has caused a reduction in aviation demand, as testified by the large literature on the topic, particularly in the context of Europe and Asia (e.g., Behrens and Pels, 2012; Fu, Zhang and Lei, 2012; Park and Ha, 2006). In the case of Australia and other large continental countries such as Brazil, Russia, India, Canada and the USA, the implementation of high-speed rail projects has been minimal or non-existent, providing air transport with a predominant competitive advantage, particularly in terms of faster travel time and higher frequency than other modes of transport. 
From the airline's perspective, the choice of a particular destination should take into consideration the airport's location and infrastructure, the cost of operation (including slots and congestion) and eventually, competition with other airports (Graham, 2013). Larger airports closer to city centres are usually busier, not only because of the volume of passengers arriving and departing but also because of the number of passengers in transit. Most airlines use larger metropolis-based airports as a hub and charge a premium, particularly during peak hours. Airport infrastructure is also important and is related entirely to the cost of operation: Larger airports tend to be more expensive than secondary airports. Another factor the airline might consider is the airspace at a specific airport. Air-traffic flow management (ATFM) has recently been developed to analyse and improve air traffic networks and can help airports and airlines increase their service volumes and decrease their delays (Geng and Cheng 2007). However, an airline can suspend a less-profitable service if the airspace is unable to absorb services. It can also divert traffic to other airports, particularly when several airports serve the same region (Wang and Song, 2010).

Garrow (2010) highlights the role of regulation, both domestic and international, as a factor that influences air transport, particularly in terms of fuel costs, airport growth in urban areas and the ability to foster (or not) market competitiveness.

Non-aviation factors. Geo-economic factors are not within airlines’ control; instead, they are influenced by the economic activity and geographic characteristics of the locations that they serve. Examples of geo-economic factors include regional economic activities, government regulations, national and global economic issues, social and political stability, and climate and location from a geographical perspective. 
Socio-political-economic issues directly affect air transport demand. In particular, population income relates to the financial ability to travel, particularly on leisure routes, where business-sponsored trips are not preponderant. Economic and financial trends also affect airfare prices, which ultimately directly affect the affordability and likelihood of air travel. A population's income is also directly linked to regional economic activities such as mining, agriculture, tourism, industry, and the volume of the corporate travel/freight market. If the regional economic activity of an outbound market is not prosperous or if a country is undergoing an economic or political crisis, the population's willingness to travel and companies' budgets for travel will be affected, thereby influencing domestic and international demand in both the leisure and corporate markets (Chin and Tay 2001). Additionally, experience has shown that attempts to increase transport taxation have been resisted by transport providers (Li, Gao \& Wang, 2012); in most cases, an increase in the overall price of tickets affects the demand for aviation and nonaviation means of transport (Mak, 2008), particularly in the leisure segment. Social issues that are not purely linked to the economy-e.g., wars, violence, terrorism and religious conflicts—can also interrupt/disrupt air services (Mason, 2005; Santos \& Haimes, 2004).

Geographic characteristics, which may affect demand in either a negative or a positive way, are central to the air route suspension decision-making process. Two main geographic factors affect demand: location and climate (Calderón 1997). Location affects demand in that the distance of the destination from the traveller and the time spent for travelling both influence the demand for competing destinations. Climate is another factor that has a direct effect on tourism: Climate and weather support tourist and recreational activities and define tourism's central locations (Martín 2005). Climate can either be the reason for a vacation or it can be a support, resource, locational factor, or attraction. Climate and severe weather change can also affect 
tourism seasonality and have a minor effect on the decision to suspend routes, although if consistent and repetitive in the long term, they can affect the brand of a destination and reduce its appeal to tourists.

Seasonality affects not only aviation but also the entire tourism industry. Seasonality includes two major factors—natural (physical) and institutional (social and cultural)— which involve both the origin and destination regions (Pegg et al. 2012). Natural seasonality refers to variations in natural factors, such as climate, weather, seasons, and levels of rainfall, snowfall, or sunlight. Institutional seasonality is related to living/cultural behaviour, such as school holidays, public holidays, the length of time available, the necessary travelling gear, and the motivation for travelling, such as events and festivals. To evaluate the dimensions of demand and support to overcome seasonality, airlines use revenue management, which allows airlines to adjust fares to balance supply and demand (Cleophas, Frank, and Kliewer 2009). Airlines have cancelled routes at specific times during the year due to low demand that does not cover operational costs. A case study in the Australian literature (Pegg et al. 2012) includes the Alpine area of New South Wales, which is a popular ski destination, although global warming and infrastructure issues have increased doubts about ski operations in this region.

\section{Stakeholders' Engagement}

Airlines, airports, and DMOs have major commercial interests in avoiding air route suspension. Each party's role in the process and primary interests are discussed in more depth below.

Airlines are the main stakeholder in the decision to suspend a route, and they pay particular attention to the route's cost structure and overall profitability. Airport infrastructure 
and costs are also important factors in the airline decision-making process. Typically, airlines have a budget for delays, and if an airport's delay volume is excessive due to airport operation performance failures, the airline may decrease service frequency or suspend services at that airport (Zou and Hansen 2012). Another cost factor is the groundside operations cost (including labour costs). Certain processes, such as check-in, baggage handling, catering, load-planning control, and aircraft pushback from the passenger bridge tend to be slower during peak times or in busier airports, making such operations more expensive (Kemppainen et al. 2007). Another method for demand management is to introduce larger or smaller aircraft (Swan 2002).

At busy airports, a barrier to air route extension and a factor in air route suspension can be slot availability. Strategies to increase flight schedules or introduce new routes are only as effective as the available airport capacity can allow. Thus, this capacity is an important barrier to market entry (Babic and Kalic 2012). However, an additional circumstance that may lead to the suspension of an unprofitable air route is competition with a more profitable route relative to the allocation of aircraft and slot availability. In this respect, professional network management is paramount for profitable airlines (Niehaus et al. 2009). This process controls route implementation through three steps: planning, operation, and revenue management. In addition to these factors, risk management and performance measurement are key aspects related to safety and security that an airline will consider before establishing a new air route involving a specific airport (Aghahowa and Allen 2007).

The relationship between airports and airlines is crucial to avoiding air route suspensions. Airports and airlines are related through various forms of agreements. Airport-airline interactions include having a signatory airline for an airport, airline ownership or control of airport facilities, long-term use contracts, airport revenue-bond issuance to airlines, and revenue sharing between 
airports and airlines (Barret 2004). Thus, numerous factors can both influence the relationship between various businesses and directly affect air route suspension. For airports, long-term contracts with airlines are advantageous because airlines manage key airport facilities, infrastructure, and airport revenues. Airlines also support airports by creating facilities and infrastructure specific to their customers (Fu et al. 2011), such as lounges near gates and smoother connection procedures.

Certain airports either offer lower fees to attract more flights or provide incentives to maintain specific routes. Allroggen, Malina and Lenz (2013) have conducted a study on the factors that influence the presence of incentives for route development among European airports. They have concluded that incentives increase on business routes and that airports are more likely to offer incentives (i.e., lower fees and charges) if their standard charges are high, whereas they are less likely to offer incentives if competition from other airports is high. Because 'sharing investment costs can reduce financial risk' (Albers et al. 2005, p. 53), some airports form exclusive contracts with certain airlines (Fu et al. 2011); airlines prefer to have their own hubs rather than to share with other airlines. This makes the relationship between a specific airport and airlines even more competitive.

DMOs are also key stakeholders in the context of this study. Many local/regional/state/national governments have established a specific body responsible for developing tourism in a particular destination or area. In recent years, many destinations have created DMOs, thus improving their tourism structure and operations and making themselves more attractive. DMOs often develop a tourism destination’s marketing strategy (Bornhorst et al. 2010) and in some cases, they create joint initiatives in which they co-invest with major airlines to promote particular routes. 
Cooperative strategies. One strategic way to expand market share and increase seat capacity is through code-share agreements (Du et al. 2008). Other agreements have also been used, including connecting airport gate proximity and frequent flyer program cooperation (Brueckner 2001). However, this type of cooperation introduces certain conflicts, and its strategic objectives should be clear before an alliance network is created (Hsu and Wen 2003). Several empirical studies have investigated the effects of such alliances (Goh and Yong 2006; Du et al. 2008; Iatrou and Alamdari 2005; Goetz and Shapiro 2012); most such investigations have shown that under such agreements, airfares decrease and market share then increases. This strategy allows carriers to extend their networks effectively without the costs associated with operating their own equipment (Brueckner 2001), thus avoiding interruptions in service.

\section{Method}

In this research, we used both primary and secondary data to fulfil the research objectives. Primary data were collected through interviews with key stakeholders in the aviation market who have information on the decision-making process for suspending air transport routes. Semistructured interviews were effective because they provided deep insight into the current market and background for air route suspension. Due to the difficulties in obtaining access to traditional airline data sources such as booking and ticketing databases (e.g., airlines’ computer reservation systems and flight and schedule (e.g., Official Airline Guide - OAG) and operational databases) (Garrow, 2010) that could inform particular air route suspensions, we mapped out a considerable amount of media information to develop a better understanding of real air route suspension cases and had our interviewees elaborate further on those particular cases. 
Participants in the interviews included managers and directors from Australian airports that have experienced route suspension (as in Table 1), domestic airlines, and DMOs affected by suspended routes. Most of the participants were approached via email. Stakeholders' contacts were taken from either their organizations' websites or LinkedIn. Of the 20 emails sent, four recipients gave no response at all and three were unavailable to participate in the research. Ultimately, we conducted 13 interviews: One participant was from a low-cost domestic airline (Tiger Airways), seven were from airports (Adelaide, Brisbane, Canberra, Darwin, Gold Coast, Mackay and Perth), and five were from DMOs (Gold Coast, Tasmania, South Australia, and Western Australia). Pseudonyms were used to preserve the identity of the respondents and their organizations although in some cases, we had permission to state the organization to which the interviewee belonged. The interviews were recorded and after considering the specific cases of route suspension gathered from newspapers or indicated by the interviewees, we searched for further contacts to obtain information about other professionals involved with the case who could contribute to the research. All of the interviews were transcribed to permit further analysis. To the greatest extent possible, we relied on respondents' own words to give voice to these stakeholders. In many cases, this practice is neglected in the academic literature on air transport management.

The transcriptions of the interviews were analysed using the software NVivo (QSR International), which helps cluster the main themes and topics mentioned during the interviews. The data were then coded according to themes identified in the literature or that recurred during the interviews, and the themes were analysed according to the research objectives. A final draft of the current paper was then emailed to all of the interviewees so that they could provide comments about the accuracy of this paper and the quotes included in it. 
Secondary sources, particularly newspapers, were used to identify examples of air route suspensions in Australia between 2008 and 2013, including their causes and circumstances, which provided background information for the interviews (see Table 1). The objective of mapping these examples was to engage the interviewees and to conduct a further investigation into their knowledge surrounding the research aims. One common feature of the routes presented in Table 1 is that they usually connect a state/territory capital city (e.g., Adelaide, Brisbane, Darwin, Melbourne, Perth and Sydney) with a leisure or regional destination (e.g., Cooma, Gold Coast, Griffith, Kalgoorlie and Mackay). The airlines identified have diverse business models, such as low-cost carriers (Tiger Air and Jetstar), regional carriers (Rex Airways and Skywest) and full-service network carriers (Qantas). During the interviews, other cases emerged.

Table 1. Examples of Route Suspension in Australia from 2008-2013

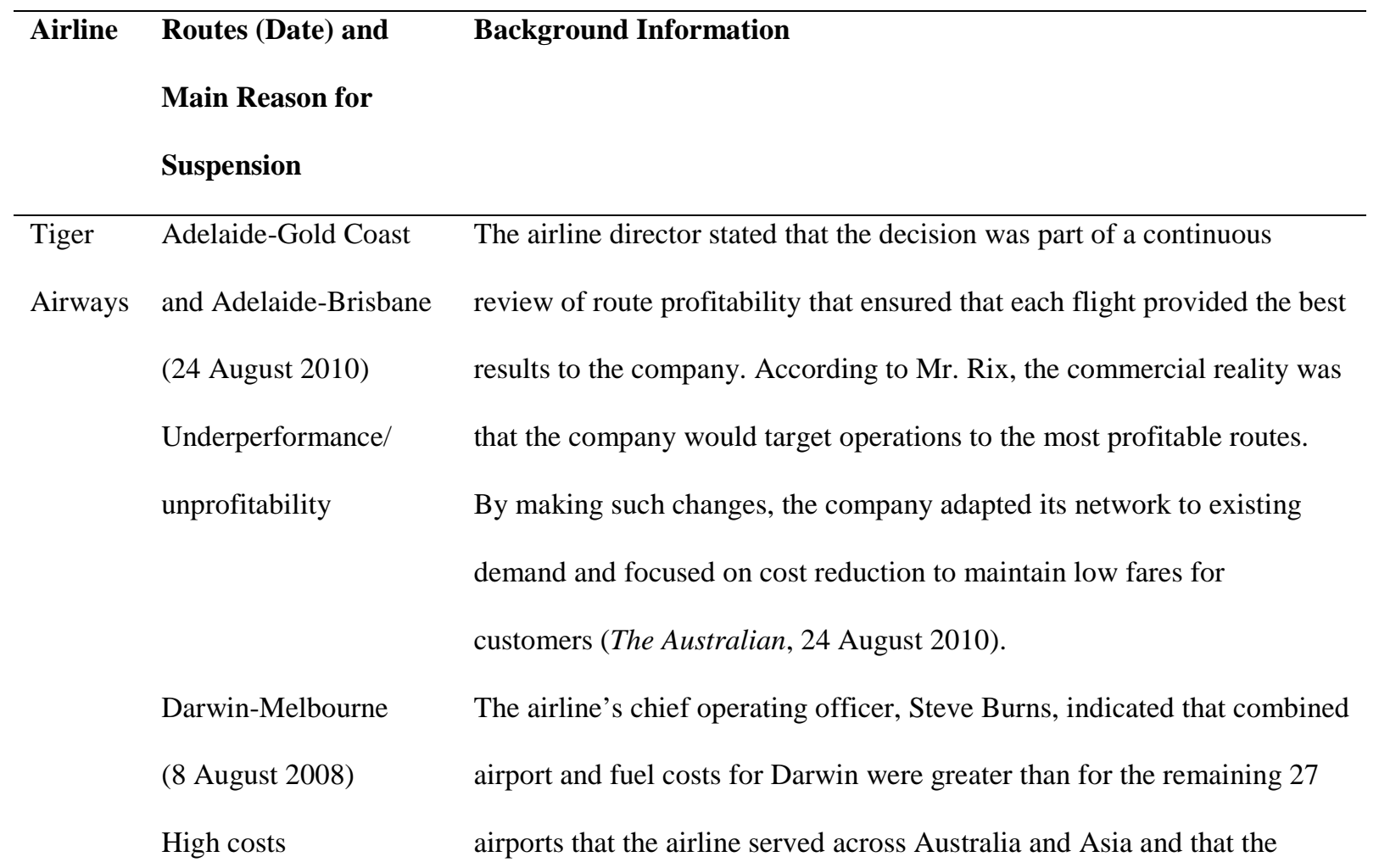


operation of a true low-fare airline was incompatible with a high-cost destination (Northern Territory News/Sunday Territorian, 8 August 2008).

Rex Sydney-Cooma

Airways (May 2008)

Pilot shortage

Griffith-Melbourne

(11 May 2012)

Unprofitability

Qantas Mackay-Brisbane

(26 February 2008)

Pilot turnover

All operation from

Gold Coast airport

ceased

(July 2008)
The airline attributed the service suspension to a pilot shortage, high attrition rates, and aggressive recruiting by major airlines.

The relationship between the Griffith City Council and Rex was turbulent. According to The Area News, Rex suspended flights from Griffith to Melbourne on 11 May 2012 due to unprofitability. The city’s Business Chamber spokesman, Paul Pierotti, declared that the route was unprofitable because of poor administration by Rex, leading to high prices and unsatisfactory scheduling. The city government unsuccessfully attempted to reach a consensus with the airline, although the runway had been lengthened to accommodate larger aircrafts. Other airlines, such as Qantas Link and Virgin, were approached, but they were not interested in investing in the route (The Area News, 11 May 2012).

Qantas announced on 26 February 2008 that it would suspend the Mackay-to-Brisbane route due to an abnormally high pilot attrition rate. Additional actions included an upgrade to a larger aircraft in certain services to maintain capacity (ABC News, 27 February 2008).

In July 2008, Qantas Airways decided that its low-cost carrier, Jetstar, would be solely responsible for leisure routes to the Gold Coast airport. According to ABC News, the decision was criticized by both customers and industry professionals. Consumers complained about the interruption of their Qantas benefits, which they would not have with Jetstar. Those benefits included frequent flyer points, the transfer of checked baggage, and complimentary terminal bus-transfer transportation in Sydney (ABC 
News, 05 August 2008). Qantas resumed flights from the Gold Coast to Sydney in October 2012, stating that demand had increased, particularly in the corporate market. Qantas is still studying the option of flying from the Gold Coast to Melbourne (ABC News, 14 August 2012).

Skywest Kalgoorlie-Melbourne The airline informed city leaders that this route was operated at an (31 July 2008) average 50\% load factor, which was not viable. The city mayor indicated

Fuel costs and that the city council was willing to offer incentives to the airline to avoid economy crises limiting air travel to the Eastern states for the Kalgoorlie region. The focus would be on promoting Kalgoorlie as a tourist destination in major cities, such as Melbourne, Sydney, and Adelaide. However, Skywest did not reverse its decision; however, in January 2010, it did reinstate weekend service (The West Australian Newspapers, 31 July 2008).

Jetstar Gold Coast-Perth

(October 2013)

Insufficient demand and unprofitability
In July 2013, Jetstar announced the suspension of the Gold Coast-to-Perth route. The reason was insufficient demand and unprofitability, which prompted the airline to decide to use the aircraft for another route (Crikey, 12 August 2013). Although Jetstar also announced the suspension of the Gold Coast-to-Hobart route due to unprofitability, there was no prolonged coverage of the story by the media.

Sources: Various newspapers.

\section{Background of Domestic Airlines in Australia}

Domestic aviation was deregulated in Australia in 1990, ending 30 years of government control over capacity, fares, industry entry and aircraft importation. Between 1990 and 2000, deregulation changed Australia's domestic air transport sector in the following ways:

1. New domestic operators could enter the market and compete over fares, service quality and schedules. In 1992, changes were announced to the aviation policy, 
allowing Qantas Airways to operate certain domestic routes to connect the domestic and international markets more effectively. (Until then, Qantas had operated exclusively internationally; Grimm \& Milloy, 1993.)

2. Five years after deregulation, domestic air passenger volume doubled from 1980s levels. This increase was due to population growth, tourism development and passengers who flew for the first time immediately after deregulation and were willing to pay more for air travel. Certain changes in service quality further affected the growth of demand, such as greater flight frequency, loyalty bonuses and airport lounges (Quiggin, 2002).

The 2000s were characterized by a number of new initiatives that in one way or another have influenced the overall background related of some the airlines mentioned in this study. One example is the introduction of Virgin Blue, on 31 August 2000, which began its operations with a two-aircraft fleet and the following year expanded to serve 14 new domestic routes. In 2004, Skywest, a regional airline, became part of the Virgin Group. In September 2001, Ansett collapsed after operating for over 65 years, affecting many air-transport-dependent regional centres (Wilson, 2002). In 2002, a consortium of businessmen comprised of a group of Singaporean investors and Australian private investors eventually reached an agreement with two sets of administrators, the government, unions and employees to purchase the Hazelton and Kendell passenger airline businesses. This arrangement produced Regional Express, more affectionately known as Rex (Regional Express, 2013). Currently, Rex is one of Australia's most important regional airlines. 
In mid-2004, Qantas withdrew certain of its regional routes and segmented the leisure market with Jetstar operations only. Jetstar is a wholly owned subsidiary of Qantas; it inaugurated its Australian domestic operations in May 2004. In 2013, Jetstar was the third-largest domestic Australian airline (by market share). Jetstar is Australia's largest low-cost carrier, operating approximately 850 domestic return services per week to 19 Australian destinations (Jetstar, 2013).

Tiger Air Australia (formerly Tiger Airways and a subsidiary of Singapore-based Tiger Air) entered the market in 2004. Tiger Air Australia’s Australian operations commenced in November 2007 with two bases in Adelaide and Melbourne because it is a low-cost carrier that is focused in the leisure market. However, Tiger Air Australia was not a major competitor; in early 2011, it had a market share of approximately five percent (Prideaux \& Whyte, 2013). In July 2011, the airline was grounded for two months by the Civil Aviation Safety Authority (CASA) for serious breaches of aviation safety standards. Tiger was also forced by the Australian Consumer and Competition Commission (ACCC) to stop selling tickets during that period under the threat of a severe fine (Prideaux \& Whyte, 2013). Tiger re-entered the market with a maximum of 11 aircraft under strict surveillance by the CASA. During that period, the airline closed its Adelaide base; when Tiger restarted its operations, a Sydney base was opened (ABC News, 2011).

\section{Data Analysis and Results}

\section{Aviation and Non-aviation Factors}

Demand. As expected from the literature review (see Figure 1), the interviewees cited a lack of demand as the most important factor in air route suspension. Ten of the 13 interviewees 
mentioned (in some respect) lack of demand as a crucial aspect for route suspension.

Additionally, the interviews revealed that in some cases demand existed but that other factors had influenced a specific air route suspension. Peter, from the Brisbane airport, noted two examples of lessened demand and route failure. He stated, 'In the first one, it is a business destination, where there was a mine; when the mine finishes its work life, the reason for travel to this specific destination will no longer exist, and the route will fail.' This type of situation occurs often in Australia, where mining is one of the most important economic contributors. The second example is a leisure destination; according to Peter, 'Every tourist destination has a cycle where it grows and gets to a mature stage for a while and then starts to lose trendiness and becomes less attractive.' According to him, demand can be driven in a leisure market, but a better understanding of that market is necessary when investing in strategic marketing to the right potential travellers.

In general, the interviewees took a broad view of demand in relation to air route suspension, expressing that although demand is paramount, it is comprised of much more than a passenger's decision. Influencing demand is not an easy or simple process; it requires various market strategies to key segments and market research and cooperation between stakeholders. Sometimes, all parties' lack of involvement can be a reason for an air route suspension.

Unprofitability. Along with demand, unprofitability is one of the most important reasons for air route suspension in Australia. In 12 instances, respondents referred to unprofitability as one of the main reasons for the suspension of air routes. Although unprofitability is most often the result of a lack of demand, the interviewees indicated that it could also occur due to a failure in airline management or the capacity of available aircraft. 
Daniel, a manager at a low-cost airline, commented that before a decision is made, the airline analyses the general route performance on a regular basis and if needed, works to improve sales performance. He stated:

At the end of the day, we have to achieve some sustainability, so we would take a measured approach to understand how long we have to invest for, what [it] is going to cost us and the probability of being able to influence an improvement in of that route, overall route and route performance.

After this evaluation, they make a decision about whether to continue with or to suspend the route.

Adam, from the Perth airport, expressed a similar viewpoint. He perceived unprofitability as a key decision factor for an air route suspension. He stated:

If the airline cannot make money out of it, airports and government-driven tourist authorities can continue to fund a particular route, but at the end of the day, if the route cannot stand up alone and make money, often the decision of the airline is just to cancel it.

He believes that stakeholders’ partnerships—-such as airports and airlines working together in a marketing campaign—may be helpful market strategies. However, if these strategies fail, he believes that no other action is available to avoid the suspension of a route.

Tom mentioned a case at the Mackay airport in which Tiger Airways cut a route to Melbourne due to unprofitability. However, in his opinion, the root cause was a lack of promotion. For Tom, promotion is the key to overcoming unprofitability, and successful market 
strategies to the right market—corporate, leisure, or VFR (visiting friends and relatives)— require a thorough investigation. In Australia, it is not infrequent for airports to conduct this type of investigation, with the airport reporting its research on potential new routes to the airlines. Some examples of stakeholders' relationships that aim to promote routes are discussed further below.

Seasonality. Seasonality is more than a factor for air route suspensions. It presents a challenge to numerous destinations worldwide. The interviews showed that different approaches can be used and that the right strategy may be crucial to a route's success or failure. The seasonality factor forces all of the stakeholders involved in tourism development to work together, sharing information and creating actions to overcome its effects.

Australia’s Gold Coast is an example of a very seasonal leisure destination. According to Maria, who works at a tourism authority in Queensland, intensive work must be done throughout the year to counter seasonality. Airlines know the importance of pricing and yield in the high season (e.g., school holidays). In the low season, the tourism authority works very closely with airlines to ensure that loads and rates continue to satisfy their yield requirements. Throughout this lower demand period, the authority works in partnership with the airlines in marketing campaigns, targeting both first-time and return visitors.

Seasonality is a particular challenge for the routes of LCCs. According to Daniel, who works at an Australian LCC, the challenge is 'to get local support because the market does extend to both ends; you do need to give them the service all year round.' Because Daniel's low-cost airline predominantly targets the leisure market, it has neither the year-round corporate market to support the route's sustainability nor a partnership with another airline or alliance to increase 
seats and connect the domestic network to the international market. In Daniel's view, another strategy for controlling route performance during the low season is investment in cargo.

Socio-economic factors. Economic and social issues have a strong effect on both leisure and corporate traveller behaviour. In recent years, access to air travel has become easier as prices have become more reasonable. The interviewees suggested that a few actions could be taken to avoid a suspension related to economic factors, which are external and uncontrollable.

Maria, from a tourism authority in Queensland, believes that some routes to the Gold Coast were suspended due to a diminution of the mining market. According to her,

In the past, Virgin had direct flights from Townsville down into Coolangatta. Unfortunately, they were not able to be sustained, and again, [Virgin] had to do a reallocation of aircraft; and so now, to those regional points in Queensland where there are many fly-in fly-out miners, they are all out of Brisbane.

Simon, from a tourism authority from South Australia, also emphasized external factors:

There are external factors such as the economy, mining; we have a fairly diverse economy here, but as wherever the economy goes up now, some of the strengths are mining, defence, agriculture, wine. If one of them is not going well, it can influence the front of the plan, and it can make [it] not as profitable to fly.

At the moment, however, Simon believes that because the domestic South Australian regional market is stable and growing, there are few examples of air route suspensions.

Sarah, from the Gold Coast airport, provided two other examples of socio-economic issues that have affected Australia’s domestic air travel market in Australia, most notably the 
global financial crisis in 2008. Three other interviewees also mentioned economic factors as an important issue for air travel.

Cost is another important issue noted by interviewees, particularly with respect to smaller airports. Michael, who works at a Western Australia tourism authority, believes that regional airports' operational costs are much higher than those of capital city airports and that regional airports have difficulty covering these costs; unlike capital city airports, regional airports do not have diversified revenue. According to Michael, this deficit can be a reason for an air route suspension. Laura, from the Alice Springs airport, had a similar opinion.

Daniel, from an LCC, also referred to costs. He noted that when airlines evaluate a route's performance, they determine whether the route contributes to the entire network. He states:

If it is contributing, not all routes [...] are going to achieve route operating profit, but [it is] essential that the route primarily contributes, and if it contributes, then it can still play a major part in the total network performance.

Effect of international traffic on domestic traffic. The literature states that international links have an effect on the local economy and therefore on the domestic aviation market (Koo et al. 2013). One of the interviewees mentioned a real case in Adelaide, South Australia. Ryan, who works at the Adelaide airport, explained that Emirates began to operate to Adelaide in November 2012, creating a major effect on domestic traffic because passengers from around the country now had the option of flying to Dubai and beyond via Adelaide.

Capacity and scheduling of available aircraft. One factor that causes air route suspension is the capacity and schedule of available aircraft. Although this factor is not presented in detail in the literature, it was mentioned four times during the interviews and has had a strong effect in 
some cases. Particularly for small airports or short routes, the available aircraft and its schedule can be a decisive factor in route success or failure. In an example of a route affected by the aircraft available, John, who works at the Adelaide airport, mentioned the Adelaide-Hobart route:

Fundamentally, none of them [airlines] had the right aircraft type. Virgin has been operating with a 737 that has 163 seats; Tiger and Jetstar have been using the A320, and that is really 175 plus [seats]: the airplane is just too big for the route. To make it sustainable, we really do need a daily service, and it would ideally suit a 717, approximately 100 seats, or Embraer, with the same sort of configuration, or even a Q400, which Qantas Link operates.

Another example mentioned was the case of Jetstar between the Gold Coast and Perth. Maria, from a Queensland DMO, believes that the route was not as profitable as the airline had expected and at that time, the aircraft that Jetstar had available did not contribute to sustainable profitability. Adam, from the Perth airport, speculated that Jetstar had more interest in using the aircraft on a more profitable route because that airline had a route from Brisbane to Perth, which Gold Coast passengers can choose to fly due to the proximity of both airports.

Overcapacity. Overcapacity was mentioned four times during the interviews as a reason for air route suspension. In most cases, competition exists in routes with higher demand, including Sydney-Melbourne, Sydney-Brisbane, and Melbourne-Brisbane. All of the domestic airlines have an interest in operating along those routes. Overcapacity was considered one of the reasons for the suspension of the Gold Coast-Perth route. According to Adam, from the Perth airport: 
Considering that the Gold Coast airport is relatively close to Brisbane, there has been a significant amount of capacity out of Brisbane recently. Qantas, Virgin and Jetstar, they all added capacity to Brisbane, so that does make it a little bit more difficult for the Gold Coast route.

Laura, from the Alice Springs airport, mentioned a case at Ayers Rock, which Qantas used to serve and where Virgin began to compete. According to her, however, the Ayers Rock market was not developed and as a result, the demand was merely divided. Qantas withdrew less than 12 months later. She believes that overcapacity killed the market and that before adding competitors, an effort to grow the market must occur.

\section{Stakeholders' Engagement}

Airport role and engagement with the airlines. In the interviews, airport managers were asked what they considered the role of airports to be in avoiding air route suspension. Which actions would they put in place, and how could airport managers engage with airlines in relation to this matter?

Tom, from the Mackay airport, explained that airports usually present business cases to airlines in which they describe the type of passengers and the changes they will be able to make to keep the route sustainable. According to him, airports should constantly attempt to strengthen their relationship with airlines. Other important information that Tom shared is that each airport operates differently and that marketing strategies can differ around the country, depending on the type of segment served. 
Sarah, from the Gold Coast airport, mentioned that the airport is always looking for an airline to operate a route it believes passenger volume will support that route. If a route is suspended, the airport will do research and if the route seems viable, the airport will invest in making a business case to present to different airlines to bring the route back to the airport. With respect to leisure routes, the Gold Coast airport works in partnership with airlines and tourism bodies to drive interest in the region.

Peter, from the Brisbane airport, explained that the airport has procedures to avoid air route suspension:

We keep an eye on each of the flights...and we look at things like load factor. There are a number of reasons, there are a number of ways, which can improve a flight; maybe the time of the day does not suit the market, and maybe the aircraft type is too big or too small. Maybe there has not been enough promotion.... There is all this sort of factors, and it is almost never one thing; it is almost always a combination of things.

He mentioned that although airlines follow up on their routes, airports should also monitor activity in their overall catchment areas and the destinations they serve.

Laura from the Alice Springs airport believed the airport's main role in avoiding air route suspension is to build business cases for the airlines because those cases give the airlines all of the information they need in relation to the route, such as the aircraft type needed, how feed traffic will work, how pricing can work, and which market to target. Airlines will also conduct research to check whether these data are accurate. However, because case building is expensive, she agrees stakeholders must invest in partnerships. 
Steven, from the Canberra airport, had a different opinion from the other interviewees. He believed that although involvement between airlines and airports has been increasing, much remains to be done. He particularly noted limited cooperation caused by airlines' failure to share yield information with any organization.

I guess the information available to airports it is only dealing with one half of the equation. You maybe been told you are getting a 75\% load factor, which for most airlines is in profitable territory, but that load factor, as I said, it is only telling you part of the equation. You need to understand the yield. The airline keeps that very close to its chest.

In his opinion, when airlines decide to withdraw service, they typically provide very little notice to the airport — usually four to six weeks or less. When the airport is notified, the decision has already been made, which leaves no opportunity for the airport to introduce an action plan to avoid suspension. Ryan, from the Adelaide airport, seemed to support this claim.

Finally, looking at the other side of the relationship, Daniel from Tiger Airways mentioned that airlines and airport partners work together to help one another understand the challenges presented by a market to achieve some sustainability in the routes along which the airline operates. For Tiger Airways, airports can help significantly in terms of sharing overall data and providing information about the location of new feeder markets; large airports have significant route-development teams. He believes that a healthy partnership is possible, even in light of the confidentiality and sensitivity of information, since because these partners also work with other airlines. According to him, route sustainability is about transparently sharing 
knowledge and creating not only a corporate marketing spending plan but also a corporate marketing strategy.

DMOs' role and engagement with airports and airlines. DMO managers were asked to identify their main roles in avoiding air route suspension and how they engage with airports and airlines in regard to this matter.

Simon, from a South Australian DMO, believed that the main role of a DMO is to drive travel demand for the destination, focusing on marketing to maintain and increase the movement of travellers and consequently to improve airlines' load factors. The DMO maintains a relationship with airlines to attract more routes and to follow up on existing routes, and it maintains a relationship with airports to share information and to maintain the destination's success. However, he stated that a DMO is better able to influence international markets than domestic ones because domestic markets are more stable.

Maria, from a Queensland DMO, explained that because the region predominantly attracts leisure travellers, there is much more demand during school holiday periods than at other times of the year. During the low season, the DMO tends to work more closely with airlines to increase demand through marketing campaigns to ensure that load factors are high enough to keep routes sustainable. According to Maria, the main challenge in relation to engagement with airlines is that LCCs have shrunk their staff teams and now have fewer marketing planners. Regarding the avoidance of air route suspension, she stated that route information first goes to the airport, which will involve the DMO if necessary to invest in marketing both to stimulate the market and to promote a new air route to the region. 
The interviews showed that in some destinations the stakeholders work very closely with each other, whereas in others, these relationships remain to be developed. Overall, the stakeholders agree that although avoiding air route suspension is a challenge, avoidance is easier when stakeholders develop partnerships and share knowledge.

\section{Discussion}

\section{Aviation and Non-aviation Factors}

The interviews revealed demand as the main factor for air route suspension. Regardless of the context, a lack of demand is usually the consequence of another factor, such as seasonality or socio-economic issues (Calderón 1997). The interviews demonstrated that demand can be influenced in some ways, particularly in relation to geographic characteristics, because such characteristics can be highlighted to the target market. In relation to economic activities, challenges exist—for example, it is difficult to influence demand during an economic crisis.

Unprofitability is a result of a lack of demand, but the causes of reduced demand need further investigation. This study discusses various factors that can result in a lack of demand and consequently, unprofitability. The literature relates unprofitability to a failure in airline management because profitability in aviation involves elements such as air traffic forecasting, profit cycles, airline growth, and survivability (Chin and Tray 2001). The interviews support the literature in this case; interviewees mentioned failure in airline management as a cause of unprofitability. Seasonality also influences demand and consequently, unprofitability. Although climate and location are linked to seasonality, interviewees did not specifically refer to them. Both the interviewees and the literature state that to overcome seasonality, tourism destinations 
and airlines need to have a strategic plan that aims to promote the destination all year round (Pegg et al. 2012).

Although socio-economic issues have a strong effect on the tourism and aviation industries (Chin and Tay 2001), the airlines do not control socio-economic factors (Calderón 1997) and the interviewees believe that if an economic issue affects a route, little can be done to address it. The economy affects demand and consequently profitability in both positive and negative ways. Both leisure and corporative tourist markets are affected by socio-economic factors. Additionally, the interviewees emphasized the importance of air transport to regional development, which is also supported by the literature (Smyth et al. 2012) and explains the effort of airports and DMOs to avoid air route suspensions and to work continuously to attract new services.

The interviewees revealed two important cases of routes suspended because of the capacity and availability of the right aircraft. The argument in this case is whether the airline has an interest in investing in aircraft for a specific route because the larger aircraft would likely offer greater flexibility across the entire network. Additionally, passengers prefer larger aircraft because they offer a higher-quality experience (Calderón 1997). Another important factor neglected by the literature on route suspension is overcapacity. Overcapacity may have contributed to the suspension of the Gold Coast-Perth route because this route is offered by three airlines from Brisbane.

\section{Stakeholders’ Engagement}

Airport role and engagement with airlines. The interviews revealed that larger airports' relationships with airlines flow more easily than do those of small airports, primarily because 
large airports' routes are more profitable and set-up costs are absorbed more quickly. Although the literature states that certain daily operational processes might be more expensive and slower during peak times (Kemppainen et al. 2007), the interviewees revealed that airlines know that operating in larger airports increases the chance for success.

Interviewees mentioned that most airlines do not have the resources or the time to house research teams. One successful exception is the Gold Coast airport, which developed a business case and used the data gathered to persuade Qantas to restart its operations in 2012. Because most of Australia's larger metropolitan airports are privately owned, profitable routes are important both to them and to the airlines because private companies are focused on maintaining sustainable business. The interviewees revealed that the main reason airports collaborate with airlines is to participate in information and data gathering both to avoid air route suspensions and to establish new services.

DMO role and engagement with airports and airlines. The interviewees emphasized the differences in the relationship between airports and airlines and among DMOs, airports and airlines. DMOs demonstrated a closer relationship with airports because they both represent the same region in the industry. Airlines engage with DMOs when they need to improve demand from specific regions or to market new services. With respect to the relationship between DMOs and airports, the interviewees emphasized that they usually work together, although airports have more access to information than do DMOs, which become involved either when a route is not doing well and needs promotion or when a new route is launched.

The interviews revealed some level of engagement, and the relationships can differ according to the region. However, this interaction does not occur on a regular basis because airlines are not easily accessible. Like airports, DMOs usually do not have the opportunity to 
establish a strategy to overcome the issues that cause suspensions and thus to avoid them. Although DMOs are a strong marketing force, the interviewees revealed that airlines are interested in collaboration only when they remain interested in investing in a route that is not performing well. Conversely, if an airline has already decided not to invest in a specific route, it will not engage with the DMOs involved but instead will usually communicate the suspension and reallocate its fleet.

\section{Conclusion}

This research set out to address two specific objectives to investigate the suspension of domestic air routes in Australia. These research objectives were to identify and discuss the main factors contributing to air route suspension in the Australian domestic scheduled aviation market and to identify and discuss the main roles of directly related stakeholders_-airports, airlines and DMOs—in the process.

In relation to the first objective, we found that the literature suggests most of the factors, almost all of which are related to demand (Calderón 1997). Lack of demand is a consequence of other factors, such as profitability, seasonality, and socio-economic factors. The interviews confirmed these factors. However, whereas the literature mentions factors such as geography (Calderón 1997) and business strategies (Brueckner 2001), the interviewees did not emphasize those aspects. Additionally, although factors such as the capacity and schedule of available aircraft (which is unrelated to demand) and overcapacity were not widely acknowledged in the literature, interviewees saw these aspects as important factors in Australia's cases of air route suspension. 
Addressing the second objective, the interviewees confirmed the information available in the literature related to the stakeholders' roles in avoiding air route suspension and their interrelationships with each other. We conclude from this research that in the Australian domestic market, airports' major role is related to their ability to conduct location-specific market research. The right interaction with DMOs and connecting these data resources to the marketing approach, makes the destination image more appealing to the appropriate target market. Consequently, this information usually triggers airlines' interest in the region, saving routes from suspension or reinstating previously suspended routes and creating new routes. DMOs also play an important role: They promote the destination and engage with local businesses to increase demand. They also engage with travel agencies and airlines by supporting and promoting events. The DMOs' role is supported by the literature (Bornhorst et al. 2010).

With respect to the airlines' role, we conclude from this research that although airlines seek profitability, market share is also important. In addition to conducting research themselves, some airports also offer incentives to airlines. These incentives contribute to the retention of some routes and the instatement of new routes; alternatively, they add investments to develop marketing. This study concludes that in most cases, DMOs and airports have the power to influence demand. However, the final decision comes from the airlines, which use the information provided by airports and DMOs and engage with them when doing so is both viable and useful.

These results should be considered not only in the particular context of Australia's domestic aviation sector but also in regard to the limitations of the examples/cases identified in the written media. If resource constraints are not as limited as in the case of this research, future studies in this topic can benefit, e.g., by analysing route suspensions from airline databases, 
particularly the OAG. Additionally, this study is limited because it focuses on the suspension of scheduled routes that may possibly be served by other forms of air transport, such as charter services, which can pick up the demand left by schedule domestic airlines. Nevertheless, the study establishes a foundation for better understanding air route suspension from which additional research can be developed, particularly to examine the following issues in more detail: (1) the challenges faced by regional and leisure routes because trunk routes between major commercial hubs seem less likely to be suspended; (2) the perspective of airlines and the views of their managers in regard to key factors associated with route suspension (a limitation in this study was having access to only one airline manager), particularly examining these challenges from various airline business models (low-cost carriers, hybrid airlines, full-service network carriers, regional airlines and charters); and (3) further examining the strategic opportunities among aviation and non-aviation stakeholders to strengthen and establish air routes so that suspensions can be avoided. 


\section{References}

ABC News. (2011, Aug 10). Tiger Airways grounding lifted. Retrieved from http://www.abc.net.au/news/2011-08-10/tiger-airways-casa-announcement/2833392

Aghahowa, E., and Allen, S. (2007). “Developing Key Performance Indicators for Airport Safety and Security.” Facilities, 25 (7/8): 296-315.

Albers, S., Koch, B., and Ruff, C. (2005). Strategic alliances between airlines and airportstheoretical assessment and practical evidence. Journal of Air Transport Management, 11(2), 49-58.

Allroggen, F., Malina, R., \& Lenz, A.-K. (2013). Which factors impact on the presence of incentives for route and traffic development? Econometric evidence from European airports. Transportation Research Part E: Logistics and Transportation Review, 60, 4961.

Baker, D., and Donehue, P. (2012). Remote, rural, and regional airports in Australia. Transport Policy, 24, 232-239.

Bazargan, M. (2004). Airline Operations and Scheduling. Aldershot, England: Ashgate. Becken, S., and Lennox, J. (2012). Implications of a long-term increase in oil prices for tourism. Tourism Management, 33(1), 133-142.

Behrens, C., and Pels, E. (2012). Intermodal competition in the London-Paris passenger market: High-Speed Rail and air transport. Journal of Urban Economics, 71(3), 278-288. 
Bieger, T., Doring, T., and Laesser, C. (2002). Transformation of business models in the airline industry - impact on tourism air transport and tourism: $52^{\text {nd }}$ Congress 2002, SalvadorBahia, Brasil (pp. 49-80). St. Gallen: AIEST.

Bornhorst, T., Brent Ritchie, J. R., and Sheehan, L. (2010). Determinants of tourism success for DMOs \& destinations: An empirical examination of stakeholders' perspectives. Tourism Management, 31(5), 572-589.

Bråthen, S., and Halpern, N. (2012). Air transport service provision and management strategies to improve the economic benefits for remote regions. Research in Transportation Business \& Management, 4, 3-12.

Brueckner, J. K. (2001). The economics of international code sharing: An analysis of airline alliances. International Journal of Industrial Organization, 19(10), 1475-1498.

Calderón, J. (1997). A demand model for scheduled airline services on international European routes. Journal of Air Transport Management, 3(1), 23-35.

Chin, A. T. H., and Tay, J. H. (2001). Developments in air transport: Implications on investment decisions, profitability and survival of Asian airlines. Journal of Air Transport Management, 7(5), 319-330.

Cleophas, C., Frank, M., and Kliewer, N. (2009). Simulation-based key performance indicators for evaluating the quality of airline demand forecasting. Journal of Revenue \& Pricing Management, 8(4), 330-342.

Dobruszkes, F., and Mondou, V. (2013). Aviation liberalization as a means to promote international tourism: The EU-Morocco case. Journal of Air Transport Management, 29, 23-34 
Du, Y., McMullen, B. S., and Kerkvliet, J. R. (2008). The economic impact of the ATA/Southwest Airlines code-share agreement. Research in Transportation Economics, 24(1), 51-60.

Duval, D. T. (2013). Critical issues in air transport and tourism. Tourism Geographies, 15 (3), 494-510.

Duval, D. T., and Schiff, A. (2011). Effect of air services availability on international visitors to New Zealand. Journal of Air Transport Management, 17(3), 175-180.

Fu, X., Homsombat, W., and Oum, T. H. (2011). Airport-airline vertical relationships, their effects and regulatory policy implications. Journal of Air Transport Management, 17(6), 347-353.

Fu, X., Zhang, A., and Lei, Z. (2012). Will China’s airline industry survive the entry of highspeed rail? Research in Transportation Economics, 35(1), 13-25.

Garrow, L. A. (2012). Discrete choice modelling and air travel demand: theory and applications. Surrey \& Burlington: Ashgate.

Geng, R., and Cheng, P. (2007). Dynamic air route open-close problem for airspace management. Tsinghua Science and Technology, 12(6), 647-651.

Goetz, C. F., and Shapiro, A. H. (2012). Strategic alliance as a response to the threat of entry: Evidence from airline codesharing. International Journal of Industrial Organization, 30(6), 735-747.

Goh, M., and Yong, J. (2006). Impacts of code-share alliances on airline cost structure: A truncated third-order translog estimation. International Journal of Industrial Organization, 24(4), 835-866. 
Graham, A. (2013). Understanding the low cost carrier and airport relationship: A critical analysis of the salient issues. Tourism Management, 36, 66-76.

Grimm, C. M., and Milloy, H. B. (1993). Australian domestic aviation deregulation: Impacts and implications. Logistics and Transportation Review, 29(3), 259-273.

Hsu, C.-I., and Wen, Y.-H. (2003). Determining flight frequencies on an airline network with demand-supply interactions. Transportation Research Part E: Logistics and Transportation Review, 39(6), 417-441.

Iatrou, K., and Alamdari, F. (2005). The empirical analysis of the impact of alliances on airline operations. Journal of Air Transport Management, 11(3), 127-134.

Jetstar. (2015). Our Company. Retrieved from www.jetstar.com/au/en/about-us/our-company

Kemppainen, K., Nieminen, J., and Vepsäläinen, A. P. J. (2007). Estimating the costs of airport congestion due to fast connections. Journal of Air Transport Management, 13(4), 169174.

Koo, T. T. R. and Lohmann, G. (2013). The spatial effects of domestic aviation deregulation: a comparative study of Australian and Brazilian seat capacity, 1986-2010. Journal of Transport Geography, 29, 52-62.

Koo, T. T. R., Tan, D. T., and Duval, D. T. (2013). Direct air transport and demand interaction: A vector error-correction model approach. Journal of Air Transport Management, 28, 1419.

Li, M., Gao, G. K., \& Wang, Y. (2012). International Aviation Carbon Taxation: Game between EU and Non-EU Countries. Advances in Applied Economics and Finance, 3(2), 546-551. Liasidou, S. (2013). Decision-Making for Tourism Destinations: Airline Strategy Influences. Tourism Geographies, 15(3), 511-528. 
Lohmann, G., \& Duval, D. T. (2014). Destination morphology: A new framework to understand tourism-transport issues? Journal of Destination Marketing \& Management, 3(3), 133136.

Lohmann, G., \& Koo, T. T. R. (2013). The airline business model spectrum. Journal of Air Transport Management, 31, 7-9.

Mak, J. (2008). Taxing cruise tourism: Alaska's head tax on cruise ship passengers. Tourism Economics, 14(3), 599-614.

Martín, M. B. G. (2005). Weather, climate and tourism a geographical perspective. Annals of Tourism Research, 32(3), 571-591.

Mason, K. J. (2005). Observations of fundamental changes in the demand for aviation services. Journal of Air Transport Management, 11(1), 19-25.

Niehaus, T., Ruehle, J., and Knigge, A. (2009). Relevance of route and network profitability analysis for the network management process of network carriers. Journal of Air Transport Management, 15(4), 175-183.

O'Connell, J. F., and Warnock-Smith, D. (2012). Liberalization and strategic change in air transport: an examination of current and future variations in tourist traffic to and from Egypt resulting from policy changes at EgyptAir. Tourism Economics, 18(4), 845-870.

Olischer, F. T., and Dörrenbächer, C. (2013). Concession bargaining in the airline industry: Ryanair's policy of route relocation and withdrawal (No. 73). Working Papers of the Institute of Management Berlin at the Berlin School of Economics and Law (HWR Berlin). 
Park, Y., and Ha, H.-K. (2006). Analysis of the impact of high-speed railroad service on air transport demand. Transportation Research Part E: Logistics and Transportation Review, 42(2), 95-104.

Pearce, D. G. (2012). Frameworks for Tourism Research. Oxfordshire and Cambridge: CAB International.

Pegg, S., Patterson, I., and Gariddo, P. V. (2012). The impact of seasonality on tourism and hospitality operations in the alpine region of New South Wales, Australia. International Journal of Hospitality Management, 31(3), 659-666.

Peoples, J. (2012). Chapter 1 Pricing Behavior and Non-Price Characteristics of the Airline Industry: Introduction and Overview. In J. Peoples (Ed.), Pricing Behavior and Non-Price Characteristics in the Airline Industry (pp. 1-9): Emerald Group Publishing Limited.

Prideaux, B., \& Whyte, R. (2013). Implications for Destinations when Low-Cost Carrier Operations are Disrupted: The Case of Tiger Airlines Australia. In J. Chen (Ed.), Advances in Hospitality and Leisure (vol. 9, pp. 99-118): Bingley, England: Emerald Group Publishing Limited.

Qu, H., Kim, L. H., and Im, H. H. (2011). A model of destination branding: Integrating the concepts of the branding and destination image. Tourism Management, 32(3), 465-476.

Quiggin, J. (2002). Evaluating Airline Deregulation in Australia. Australian Economic Review, 30(1), 45-56.

Regional Express. (2015). Our company - history. Retrieved from http://www.rex.com.au/AboutRex/OurCompany/regionalexpress.aspx 
Smyth, A., Christodoulou, G., Dennis, N., Al-Azzawi, M., and Campbell, J. (2012). Is air transport a necessity for social inclusion and economic development? Journal of Air Transport Management, 22, 53-59.

Santos, J. R., \& Haimes, Y. Y. (2004). Modeling the Demand Reduction Input-Output (I-O) Inoperability Due to Terrorism of Interconnected Infrastructures.Risk Analysis, 24(6), 1437-1451.

Swan, W. M. (2002). Airline demand distributions: passenger revenue management and spill. Transportation Research Part E: Logistics and Transportation Review, 38(3-4), 253-263.

Tretheway, M. W., \& Oum, T. H. (1992). Airline economics: foundations for strategy and policy. Vancouver: Centre for Transportation Studies, University of British Columbia.

Wang, M., \& Song, H. (2010). Air Travel Demand Studies: A Review. Journal of China Tourism Research, 6(1), 29-49.

Weber, M., and Williams, G. (2001). Drivers of long-haul air transport route development. Journal of Transport Geography, 9(4), 243-254.

Wilson, S. (2002). Ansett. Fyshwick, ACT: Aerospace Publications.

Yang, W., Karaesmen, I. Z., \& Keskinocak, P. (2010). Managing uncertainty in on-demand air travel. Transportation Research Part E: Logistics and Transportation Review, 46(6), 1169-1179.

Zou, B., and Hansen, M. (2012). Impact of operational performance on air carrier cost structure: Evidence from US airlines. Transportation Research Part E: Logistics and Transportation Review, 48(5), 1032-1048. 